\title{
ON DETERMINING THE OPTIMAL LIFTING LAW OF THE WALKING PROPULSION DEVICE FOOT OF AN UNDERWATER ROBOT FROM THE BOTTOM
}

\author{
E. S. BRISKIN \\ scientific adviser \\ Department of Theoretical Mechanics, Volgograd State Technical University, \\ Lenin av., 28, Volgograd, 400005, Russia \\ Center for Technology Components of Robotics and Mechatronics, Innopolis University, \\ Universitetskaya str., 1, Innopolis, 420500, Russia \\ E-mail:dtm@vstu.ru \\ dtm.vstu.ru \\ YA. V. KALININ \\ Department of Applied Mathematics, Volgograd State Technical University, \\ Lenin av., 28, Volgograd, 400005, Russia \\ Center for Technology Components of Robotics and Mechatronics, Innopolis University, \\ Universitetskaya str., 1, Innopolis, 420500, Russia \\ E-mail: jkv@mail.ru \\ L. D. SMIRNAYA \\ Department of Theoretical Mechanics, Volgograd State Technical University, \\ Lenin av., 28, Volgograd, 400005, Russia \\ Center for Technology Components of Robotics and Mechatronics, Innopolis University, \\ Innopolis, Russia \\ E-mail:dtm@vstu.ru
}

\begin{abstract}
The problem of lifting the foot of the walking propulsion device of an underwater mobile robot is considered, taking into account the additional "compression" force acting on it. Based on the solution of the variational problem, optimal modes of lifting the foot of the walking propulsion of an underwater mobile robot are established.
\end{abstract}

\section{Introduction}

A feature of ground-based mobile walking robots is the discreteness of the interaction of the propulsion device with the ground. The phase of interaction with the supporting surface in which the traction properties of the propulsion device are realized is distinguished, and the transport phase in which the foot of the propulsion device moves in space and takes a new position on the ground. This movement includes lifting the foot above the ground and moving it to a new position in the course direction. For ground-based mobile walking robots, variants of solving the problem of transferring stop walking mechanisms are known. For example, a modified stop transfer path [1] is known, proposed in the absence of sufficient information about the surface profile, or the equation for the optimal raising and lowering of the foot of an orthogonal propulsion device [2] if such information is available. Moreover, the optimality criteria can be different and additively include indicators differing in their significance, such as, for example, the level of heat loss in the engines, the force developed by the drives, the transfer time, in general, and the raising and lowering of the foot, in particular [3]. 
A feature of walking robots moving along the bottom of a reservoir is:

- the presence of buoyancy forces affecting the forces of interaction of the propulsion device with the ground;

- a higher force of resistance to movement of the robot as a whole, and of the transported mover due to their movement in a denser environment;

- possible undercurrents that affect the transported propulsion device in an arbitrary direction; - additional resistance force acting on the foot of the mover when it is separated from the bottom during the rise $[4,5]$, due to the adsorption of gases dissolved in water and slow filtration of the liquid in the soil $[6,7]$.

The latter leads to the so-called "compression" effect, which consists in the fact that there is a significant force that impedes the shear and tearing of the propulsion device support from the bottom soil. The need to overcome this additional force leads to increased energy costs for the movement of the robot, and in some cases can lead to a stop of the robot and its further immersion in the bottom soil. Overcoming the negative consequences of the "compression" effect can go in different directions: improving the construction of supports, introducing additional mechanisms that violate the conditions for this effect to occur, as well as constructing such laws for controlling the movement of the support of a walking propulsion device that would provide a minimum of energy for lifting, a minimum of forces developed by the drive, or other performance indicators, or a comprehensive criterion that takes into account part or all of the possible quality indicators. The lifting of the foot can be carried out in accordance with various laws of the drive of its vertical movement. In this case, the force, power, heat loss level and other characteristics of the lifting process developed by the drive will depend on the selected law and you can find the conditions under which the movement will occur with the best indicators from the point of view of the researcher.

\section{Formulation of the problem}

A horizontal plate of mass $m$ and area $S$ translationally moving along the vertical axis in a liquid medium with a known permeability coefficient $k$ and dynamic viscosity $\mu$ is considered as a design scheme for the foot of a walking propulsion device interacting with soil of the bottom of a reservoir (Fig. 1). At the stage of traction mode, the plate is at rest, and at the stage of lifting, forces act on it: $m g$ - the weight of the plate, $T$ - the force developed by the drive lifting the foot of the propulsion device, $P_{0} S, P S$ respectively, the pressure force of the water on the lower and upper surface of the plate. In equilibrium $P=P_{*}$

$$
P_{*} S-P_{0} S=F,
$$

where $F$ is the buoyancy force. 


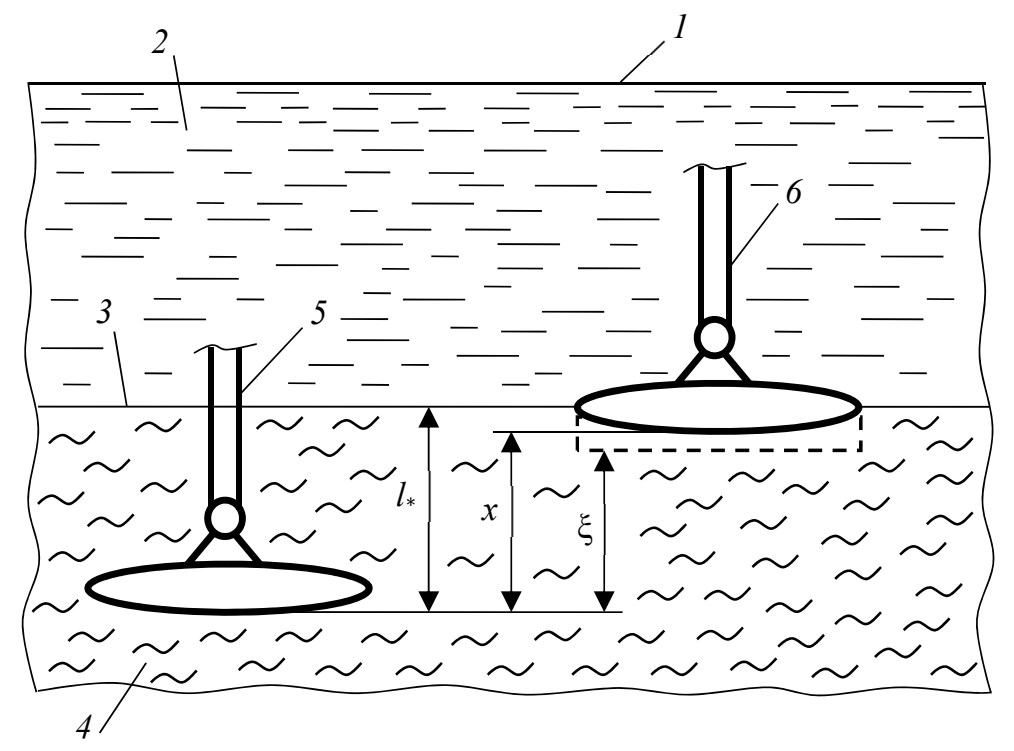

Figure 1. The design scheme of the propulsion device immersed in the ground:

1 - the surface of the reservoir, 2 - the reservoir, 3 - the boundary of the reservoir and the bottom soil, 4 - bottom soil, 5 - the support stand of the propulsion device, 6 - foot propulsion device.

When the plate moves immersed in the soil upward, a vacuum forms under it, due to the expansion of the volume of dissolved air in the liquid in accordance with Henry's law [8]. In the calculation scheme, this is taken into account by the difference in coordinates between the bottom surface of the plate $x$ and the surface of the liquid $\xi$

$$
\Delta=x-\xi
$$

In the equilibrium position of the foot with

$$
\xi_{0}=-\Delta_{0}, \quad x_{0}=0, \quad \dot{x}_{0}=0, \quad \dot{\xi}_{0}=0 .
$$

The rise of the foot is carried out with an initial zero speed under the action of the force $T$ developed by the lift drive. When the foot reaches the height $x=l_{*}$, the foot comes off the ground and the force caused by the "compression" under its lower base ceases to act on it.

The equations of motion of the foot when it is separated from the ground are compiled on the basis of Henry's law [6, 7], the law of gas expansion during the polytropic process, Darcy's law on fluid filtration [6] and the theorem on the motion of the center of mass of a solid [9]. The result is a linearized equation $[10,11]$

$$
\begin{aligned}
& \frac{m \Delta_{0} S}{\alpha\left(p_{0} S+F\right)} \ddot{V}+m \dot{V}+\frac{S}{\alpha} V+m g-F=T, \\
& \alpha=\frac{k}{\mu L}, \\
& V=\dot{x}-\dot{\Delta},
\end{aligned}
$$

where $k$ is the soil permeability coefficient, $\mu$ is the dynamic viscosity of the liquid, $L$ is the conditional height of the bottom soil column through which the filtration occurs, $x$ is the vertical coordinate of the foot.

Due to the alleged smallness in equation (4), the foot speed is understood, which is provided 
by the drive of its vertical movement.

Thus, the task is to determine such a law of vertical movement of the foot, for a given time, which ensures a minimum of heat loss in the drive motor. Heat losses [12] are determined by the integral

$$
W=v \int_{0}^{\tau} T^{2} d t
$$

where $v$ is the constant of the engine.

\section{Solution method.}

We consider a method for ensuring the minimum integral (5) based on the application of the Euler-Poisson equation with the involvement of an isoperimetric condition for the passage of distance $l_{*}$ in time $\tau$ [13].

To create Euler-Poisson equations, the functional (5) should be combined with a functional that characterizes the isoperimetric condition

$$
\int_{0}^{\tau} V d t=l_{*}
$$

Then the combined integrand function with an indeterminate factor $\eta$ has the form

$$
\Phi=v T^{2}+\eta V
$$

with respect to which the Euler-Poisson equation is compiled

$$
\frac{d^{2}}{d t^{2}}\left(\frac{\partial \Phi}{\partial \ddot{V}}\right)-\frac{d}{d t}\left(\frac{\partial \Phi}{\partial \dot{V}}\right)+\frac{\partial \Phi}{\partial V}=0
$$

In view of (4) and (7), equation (8) has the form

$$
\left[\frac{m \Delta_{0} S}{\alpha\left(P_{0} S+F\right)}\right]^{2} \dddot{V}+\left[\frac{2 m \Delta_{0} S^{2}}{\alpha^{2}\left(P_{0} S+F\right)}-m^{2}\right] \ddot{V}+\frac{S^{2}}{\alpha^{2}} V+\frac{2 S}{\alpha}(m g-F)+\frac{\eta}{v}=0 .
$$

Equation (9) is a linear, inhomogeneous differential equation of the fourth order. Its solution is known and depends on an indefinite constant $\eta$. To determine it, equation (6) should be solved taking into account $V=V(\eta, t)$.

However, to solve the problem of controlling the rise of the foot, it is necessary to determine arbitrary integration constants, and for this to adequately choose the boundary conditions if

\begin{tabular}{|c|c|c|c|c|}
\hline$t$ & $V$ & $\dot{V}$ & $\ddot{V}$ & $\dddot{V}$ \\
\hline$t=0$ & $V_{0}=0$ & $\dot{V}_{0}$ & $\ddot{V}_{0}$ & $\dddot{V}_{0}$ \\
\hline$t=\tau$ & $V_{\tau}$ & $\dot{V}_{\tau}$ & $\ddot{V}_{\tau}$ & $\dddot{V}_{\tau}$ \\
\hline
\end{tabular}
$t=0$ it is obvious that $V=0$ the other three conditions can be different.

Table 1 schematically presents the possibilities for implementing 35 different boundary conditions. In the particular case, they can be initial for the Cauchy problem.

Table 1. The possibilities for implementing 35 different boundary conditions. 
From 35 variants of the allowed boundary conditions from table 1, one should choose three corresponding to the task.

One of the solutions of equation (9), provided that at $t=0$

$$
\begin{aligned}
& V=0, \\
& \dot{V}(0)=-n u, \\
& \ddot{V}(0)=\left(n^{2}-\omega^{2}\right) u, \\
& \dddot{V}(0)=\left(3 \omega^{2}-n^{2}\right) u, \\
& u=\frac{2 \alpha}{S}(m g-F)+\frac{\eta}{v} \frac{\alpha^{2}}{S^{2}},
\end{aligned}
$$

have the form

$$
V=u\left(1-e^{-n t} \cos \omega t\right)
$$

where $n, \omega$ are defined from the system of equations

$$
\left\{\begin{array}{l}
\omega^{2}-n=\frac{B}{2 A} \\
\omega^{2} n^{2}=\frac{4 A C-B^{2}}{16 A^{2}} \\
A=\left[\frac{m \Delta_{0} S}{\alpha\left(P_{0} S+F\right)}\right]^{2} \\
B=\frac{2 m \Delta_{0} S^{2}}{\alpha^{2}\left(P_{0} S+F\right)}-m^{2} \\
C=\frac{S^{2}}{\alpha^{2}}
\end{array}\right.
$$

The graphs (Fig. 2) show the dependences of speed and coordinates at the optimal mode of lifting the foot to a height $l_{*}=0.2 \mathrm{~m}$ and in accordance with the law

$$
V=u\left(1-e^{-n t}\right)
$$

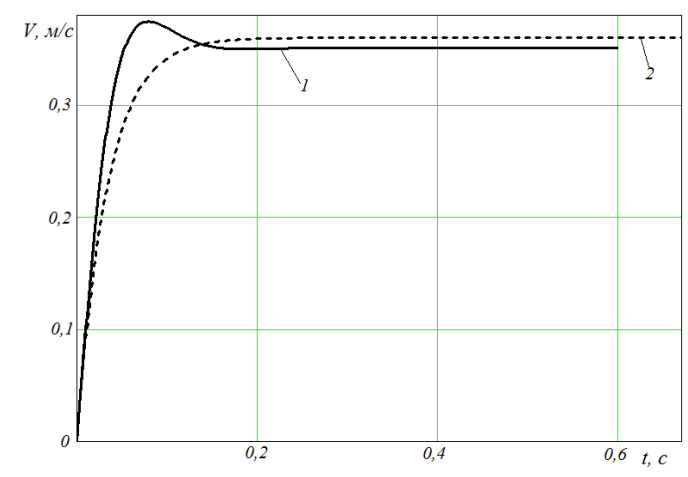

a)

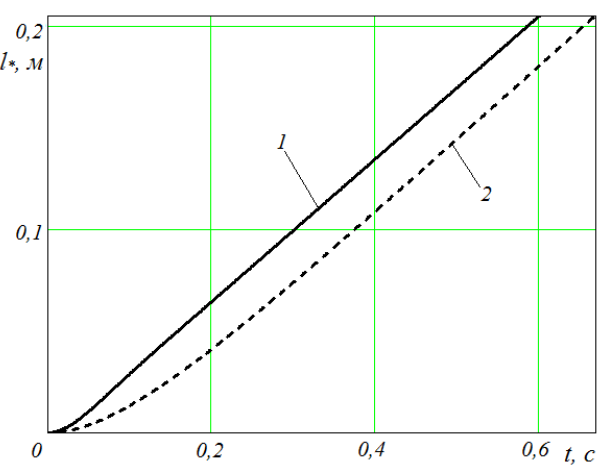

b)

Figure 2. Dependence of speed (a) and coordinate (b) with the optimal mode of lifting the foot: 1 - optimal mode; 2 - not optimal mode 
where $n=10 \mathrm{~s}^{-1}, \quad u=0.36 \mathrm{~m} / \mathrm{s}, \quad m=40 \mathrm{~kg}, \quad \Delta_{0}=10^{-3} \mathrm{~m}, \quad S=10^{-4} \mathrm{~m}^{2}, \quad \alpha=5 \times 10^{-8} \mathrm{~m}^{2} \mathrm{~s} / \mathrm{kg}$, $P_{0}=2 \times 10^{5} \mathrm{~Pa}, F=50 \mathrm{~N}$

An analysis of the results shows that the nature of the optimal modes of motion differs from the previously obtained laws of motion [10], and the energy-optimal mode by the criterion of heat loss exceeds the non-optimal one by $5 \%$.

\section{Conclusions}

A method for determining the optimal, from the point of view of minimum heat loss in the lifting drive of the walking propeller, motion modes, taking into account the additional force acting on the foot due to the "compression" effect is proposed. It is shown that due to the optimal control of the movement of the support of the walking mover, it is possible to achieve a reduction in energy losses due to resistance to the forces moving under water. This is because the description of the physical nature of the processes that occur allows us to find ways to solve the problem of using them for the good. In the future, it is planned to build a laboratory model for studying the movement of a walking mover under water and in interaction with bottom soil to verify and adjust the mathematical models proposed in this work.

\section{Acknowledgments}

The work was supported by the Russian Science Foundation (grant No. 18-71-10069).

\section{References}

1. Bessonov A.P., Umnov N.V. K voprosu o sistematike pokhodok shagayushchikh mashin [On the question of the systematics of walking machine gaits] // Mashinovedeniye. № 6. 23 p. (1975).

2. Briskin E.S., Kalinin Y.V., Maloletov A.V., Serov V.A., Ustinov S.A. On controlling the adaptation of orthogonal walking movers to the supporting surface // Journal of Computer and Systems Sciences International. T. 56. № 3. pp. 519-526. (2017).

3. Briskin E.S., Kalinin Ya.V., Maloletov A.V., Shurygin V.A. Assessment of the performance of walking robots by multicriteria optimization of their parameters and algorithms of motion // Journal of Computer and Systems Sciences International. T. 56. № 2. pp. 334-342. (2017).

4. Chernyshev V.V., Arykantsev V.V. Modelirovaniye dinamiki shtampovoy ustanovki pri vzaimodeystvii s podvodnym gruntom [Modeling the dynamics of the stamp installation in contact with underwater soil]. Izvestiya Volgogradskogo gosudarstvennogo tekhnicheskogo universiteta. 25 (152), pp. 11-14. (2014)

5. Chernyshev V.V., Goncharov A.A., Arykantsev V.V. Modeling of vibroimpact processes which occurs in feet changing of the walking units at viscoelastic grounds // V sbornike: Procedia Engineering Ser. "Proceedings of the 3rd International Conference on Dynamics and Vibroacoustics of Machines, DVM 2016". pp. 387-393. (2017)

6. Koohmishi M., Azarhoosh F. (2020) Assessment of drainage and filtration of sub-ballast course considering effect of aggregate gradation and subgrade condition. Transportation Geotechnics. Volume 24. 100378.

7. Yao Z., Chen Z., Fang X., Wang W., Li W, Su L. (2020) Elastoplastic damage seepageconsolidation coupled model of unsaturated undisturbed loess and its application. Acta Geotechnica. Volume 15. Issue 6, p. 1637-1653.

8. Memon A., Li A., Jacqueline N., Kashif M., Ma M. Study of gas sorption, stress effects and analysis of effective porosity and permeability for shale gas reservoirs. Journal of Petroleum Science and Engineering. Volume 193, 107370.

9. Golubev, Y.F. Osnovy teoreticheskoy mekhaniki [Fundamentals of Theoretical Mechanics] / M. : Izd-vo MGU,. -524 p. (1992). 
10. Briskin E.S., Smirnaya L.D. On the detachment from the ground of the walking locomotor's foot of the mobile underwater robot // Robototekhnika i tekhnicheskaya kibernetika. T. 7. № 3. pp. 215-223. (2019).

11. Smirnaya L.D., Briskin E.S. The interaction of the foot walking propulsion of mobile underwater robot with the bottom soil // Extreme Robotics. T.1. № 1. pp. 213-219. (2019)

12. Kalinin Ya.V., Briskin E.S. Energeticheskaya effektivnost' pokhodok mobil'nogo shagayushchego robota // Izvestiya Volgogradskogo gosudarstvennogo tekhnicheskogo universiteta. № 6 (185). pp. 77-81. (2016).

13. El'sgol'ts L.E. Differentsial'nyye uravneniya i variatsionnoye ischisleniye [Differential equations and calculus of variations] / 3-ye izd. - M. : Mir, - 432 p. (1983). 